\title{
The effect of weather on the decision to migrate from stopover sites by autumn- migrating ducks
}

\author{
Benjamin J. O'Neal ${ }^{1,4}$, Joshua D. Stafford ${ }^{2,5}$, Ronald P. Larkin ${ }^{1}$ and Eric S. Michel ${ }^{3^{*}}$ (D)
}

\begin{abstract}
Background: Previous investigations of autumn-migrating ducks have reported weak connections between weather conditions and the decision to migrate from stopover sites. We leveraged relatively new weather surveillance radar technology to remotely detect departures of discrete groups of various species of migratory dabbling ducks (Anatidae) in autumn to more directly assess the effect of specific weather conditions on departure from discrete stopover sites.

Methods: Using radar data collected over fifteen years (1995-2009), we documented a consistent phenomenon where a single, identifiable group departed from our study area on $30 \%$ of days during the autumn study period, and no ducks departed on the other days. We gathered weather variables from nearby stations and used them to develop competing models to explain temporal patterns of departure versus non-departure to better understand the potential mechanisms associated with binomial patterns of departures.
\end{abstract}

Results: The best approximating model of departure probability was our integrated model, which included variables accounting for wind aloft direction favorable for departure (i.e., tailwind), absence of precipitation, and a partially or completely clear sky. The integrated model accounted for all model weight in the candidate set and explained 55\% of the variation in departure probability. Estimated probability of departure was 0.76 after parameterizing the best model with favorable conditions for all covariates.

Conclusions: Our results contrasted those of previous studies of autumn duck migration as a small set of simplistic, extrinsic conditions substantially influenced departure decision.

Keywords: Anatidae, Migration, Radar, Remote sensing

\section{Background}

Throughout the course of migration, birds, bats, and other organisms make many important decisions, including where to go, how long to stay, and when to leave. Each of these decisions affects the others and ultimately contributes to the fitness of the individual [1-5]. The decision of when to migrate is especially important because it requires forfeiting existing conditions, enduring conditions aloft, and assuming risk regarding the conditions of an unseen destination. Because the timing of departures during spring has a direct effect on reproductive output, many bird species have developed endogenous mechanisms to

\footnotetext{
* Correspondence: eric.michel@sdstate.edu

${ }^{3}$ Department of Natural Resource Management, South Dakota State

University, Brookings, SD, USA

Full list of author information is available at the end of the article
}

control the timing of migration toward the breeding grounds [6]. During autumn, however, birds seem to rely more on external factors, such as food availability, predation risk, social context, and weather [7]. We contend that examining the relationships between these external factors and migratory responses can provide insight into which factors are important to specific taxa at which times and in which places $[8,9]$.

Among the environmental factors that affect the timing of autumn migration, weather has been identified as a key factor for many avian taxa $[10,11]$. Despite the extensive study of migration and weather [12], the specific role of weather in the regulation of autumn migration remains uncertain for some major avian taxa including waterfowl guilds such as dabbling ducks (but see $[13,14]$ ). 
One reason for our limited understanding of the influence of weather on duck migration is the fact that the timing of departure in ducks is especially complicated. Unlike passerines, which often operate under a timeminimization strategy [15], autumn-migrating ducks typically remain at mid-migration stopovers for multiple days, even though weather conditions suitable for migration appear present $[16,17]$. The timing of duck migration is further complicated by hunting pressure [18] and habitat quality [19].

The few published studies of migrating ducks suggest that weather has a relatively minor effect on the timing of duck departure. Indeed, Beason [20] asserted that weather "plays only a minor role in influencing autumn migration", and Bellrose [14] argued that "factors other than weather were responsible for initiating most departures of ducks." Nevertheless, weather has been shown to influence the distributions of ducks during autumn and winter [21-23], the timing of departure in other avian taxa [11, 12], and the overall migratory phenology of birds in general [24]. It follows that weather would also play a part in the temporal variation in the departure of ducks.

Previous studies have likely failed to identify the effect of weather because of the methods used to quantify the timing of departure. Rather than examining the variation in migration at a specific place and time each day, Beason [20] combined data from six radars spanning much of the southwestern United States and analyzed the peak migration traffic rate for each night across the whole study region. In addition, the birds in Beason's [20] study were only identified generally as "non-passerines." Bellrose [14] attempted to infer the daily magnitude of migration based on weekly changes in abundances of ducks, which almost certainly changed between surveys based on our understanding of turnover rates. He also tried to quantify the magnitude of the migratory response by analyzing the size of each daily departure relative to the total number of migrants for each year [14]. This approach implies that the magnitude of a migratory response at one time of year is relative to the amount of migration occurring at another time of the year, which violates the assumptions of independence for the linear regression used to analyze his continuous dependent variable. In this study, we explored how a dependent variable describing the day-to-day presence or absence of a duck departure event from an explicit location could substantially improve upon previous studies. Based on this improved approach, we predicted that there would be a measurable relationship between local weather conditions and the day-to-day timing of migration in autumn-migrating ducks. We used weather surveillance radar (WSR) to monitor the egress of ducks from a specific midcontinent stopover site over multiple years during autumn, and we relate the timing of these departures and non-departures to relevant weather conditions.

Tailwind was documented as the primary weather condition affecting the propensity for migration in many bird species, including ducks, due to its substantial effect on the net energetic cost of migration [11, 20, 25, 26]. A recent study has shown a mechanistic connection between birds' perceived degree of wind assistance, their baseline corticosterone levels, and their associated departure probabilities [27]. With respect to the direction of the wind, Erni et al. [28] reported birds distinguished between favorable and unfavorable wind conditions rather than graded wind on a continuous scale of favorability. This suggests that ducks stopping over at our study area might well be influenced by a simplistic binary mechanism associated with the direction of winds aloft relative to their preferred direction of departure.

Precipitation is another factor with the potential to regulate avian migration probability due to its impedance of flight, influence on thermoregulation $[11,15,16]$, and potential to cause mortality [29]. Therefore, we hypothesized that departure decisions among autumn-migrating ducks might be influenced in a direct way by the simple presence or absence of precipitation [30].

Departure probability can also be influenced by weather conditions that affect the orientation mechanism. For example, stars are thought to aid in the orientation of ducks and other birds during flight, so their obstruction by clouds could reduce the probability of departure $[31,32]$. Therefore, we hypothesized that duck departure might be influenced by the amount of cloud clover as well as the simple ability or inability to see some portion of the night sky and its visual cues. In addition to upward visibility, departure can also be influenced by migrant birds' ability to see terrestrial orientation. This ability is at least partially determined by the height of the cloud ceiling. Given the fact that ducks migrate through our study area at $490 \pm 163 \mathrm{~m}$ [33], we hypothesized that cloud ceilings below a threshold of $600 \mathrm{~m}$ might inhibit departure in a categorical fashion.

Air temperature is another important factor that affects the energetic balance of birds [34, 35], the progression of duck migration, and the latitudinal distribution of migrants throughout a season [21, 23]. However, the role of temperature as a proximate cue for migration initiation on a fine temporal scale (i.e., daily) is uncertain, so we included this factor in our investigation [14]. Additionally, the difference in temperature from the preceding day is another potential cue for duck departures. Some migrants, especially the early-season obligate migrants in our study, may have an environmental temperature at which they are no longer comfortable remaining at a stopover. Therefore, the minimum 
temperature for a given day may also influence the probability of departure in our study system. Barometric pressure, as well as the change in pressure, may also serve as proximate cues for future conditions at current and future locations of birds [12].

In addition to weather factors, there are also habitat factors that have been shown to influence duck migration [36]. Production of plant foods for waterfowl in our study system can vary considerably from year to year based, on a highly dynamic hydrology regime. An index for the quantification of this annual variation in foraging habitat quality has been developed and validated within our study system [37]. Concurrent studies at our study site have shown a strong relationship between this foraging habitat index and dabbling duck stopover duration [36]. If the duration of stay is influenced by this factor, it is certainly possible that the probability of departure is as well [36].

In addition to the simplistic mechanisms above, some external factors may also work together in an additive fashion to influence stopover. For example, stopover habitat suitable for migratory ducks is often isolated spatially [38]. The ability to orient to suitable habitat may be dependent on the ability to observe multiple orientation cues in the sky and/or on the ground. If this is the case, we might expect to see the height of the cloud ceiling (relative to ducks' preferred heights (400-600 m; [12]), along with amount of cloud cover and its influence on sky visibility, combining to influence the probability of migratory departure [20]. Departure probability can also be influenced by a combination of weather conditions related to the thermal environment of a bird. Current temperature and wind speed, along with anticipated future temperature (as indicated by changes in temperature from the preceding day), can have substantial effects on thermoregulation in ducks during autumn and thereby have a substantial effect on the decision to depart from a stopover [14, 20]. Finally, it is possible that factors related to energetic efficiency of flight as well as the capacity for effective orientation might influence departure probability in an additive fashion.

Our specific objectives were to: 1) screen WSR data from central Illinois to identify duck departures from a major stopover along the Illinois River; 2) develop competing models to evaluate relationships between the timing of departures and weather; 3) parameterize the relationships between individual covariates and departure probability to understand the magnitude of the effects of particular variables.

\section{Methods}

\section{Study site}

We monitored dabbling duck departures from a 14,431ha complex of wetlands and backwater lakes in central Illinois $\left(40.376055^{\circ} \mathrm{N},-90.027238^{\circ} \mathrm{W}\right.$; Fig. 1). Our study area contained several wetland types, including areas managed for growth of moist-soil plants [39], large areas of open water with submerged aquatic vegetation, floodplain forests, and shallow-water lakes [37]. Over the last several decades, Chautauqua NWR has been the most important waterfowl refuge in Illinois with respect to use, and has been designated a Globally Significant Bird Area [37, 38]. In 2006, The Nature Conservancy and the U.S. Fish and Wildlife Service restored an additional 4000 ha (Emiquon Preserve, Wilder Tract, Thompson Lake, Flag Lake), substantially increasing the amount of habitat for migratory waterfowl within this complex. These key stopovers and the surrounding wetlands are part of a migratory flyway that is vital to numerous species of birds and representative of other major waterfowl flyways across North America. Among the duck species that utilize this area, dabbling ducks (Tribe Anatini) accounted for $90 \%$ of waterfowl use during autumn migration periods from 1995 to 2008, according to aerial inventories [40]. The complex was $60 \mathrm{~km}$ west of a WSR unit (KILX) located in Lincoln, Illinois.

\section{Quantification of departure}

We downloaded level II data recorded by the KILX unit during autumn 1995-2009 from the National Environmental Satellite, Data, and Information Service (https:// www.ncdc.noaa.gov/nexradinv/). We screened all reflectivity scans $(24 \mathrm{~h} /$ day, $\geq 144$ scans/day) from October $1-$ December 31, 1996-1998, 2003, and 2006-2009, identifying duck departures according to established ground-truthed criteria [36, 41]. We could identify targets to tribe (dabbling ducks), but not to species. Although migratory behaviors may differ among dabbling duck species [31], their overall responses to weather are likely similar [23, 42]; therefore, we conducted our study at the taxonomic resolution of tribe. All departure events detected in the first eight years that we analyzed appeared on radar shortly after sunset (mean \pm $\mathrm{SD}=44 \pm 6 \mathrm{~min}$ ). Based on this finding and previous studies showing that the vast majority of dabbling duck migrations occur shortly after sunset $[20,25]$, we analyzed departures from an additional seven years (1995, 1999-2002, and 2004-2005) based solely on a two-hour period surrounding sunset (1700-1900 CST/1800-2000 CDT/2300-0100 GMT; 12 scans/day). Because our identification of radar targets partially relied on species composition identified by aerial inventories, we analyzed migratory events from the mean date at which aerial inventories were initiated each year ( 15 October \pm 2 days [SD]) through the date on which our study area was estimated to have frozen over based on field observations and daily surface temperature (A. Yetter, Illinois Natural History Survey, unpublished data). The median 


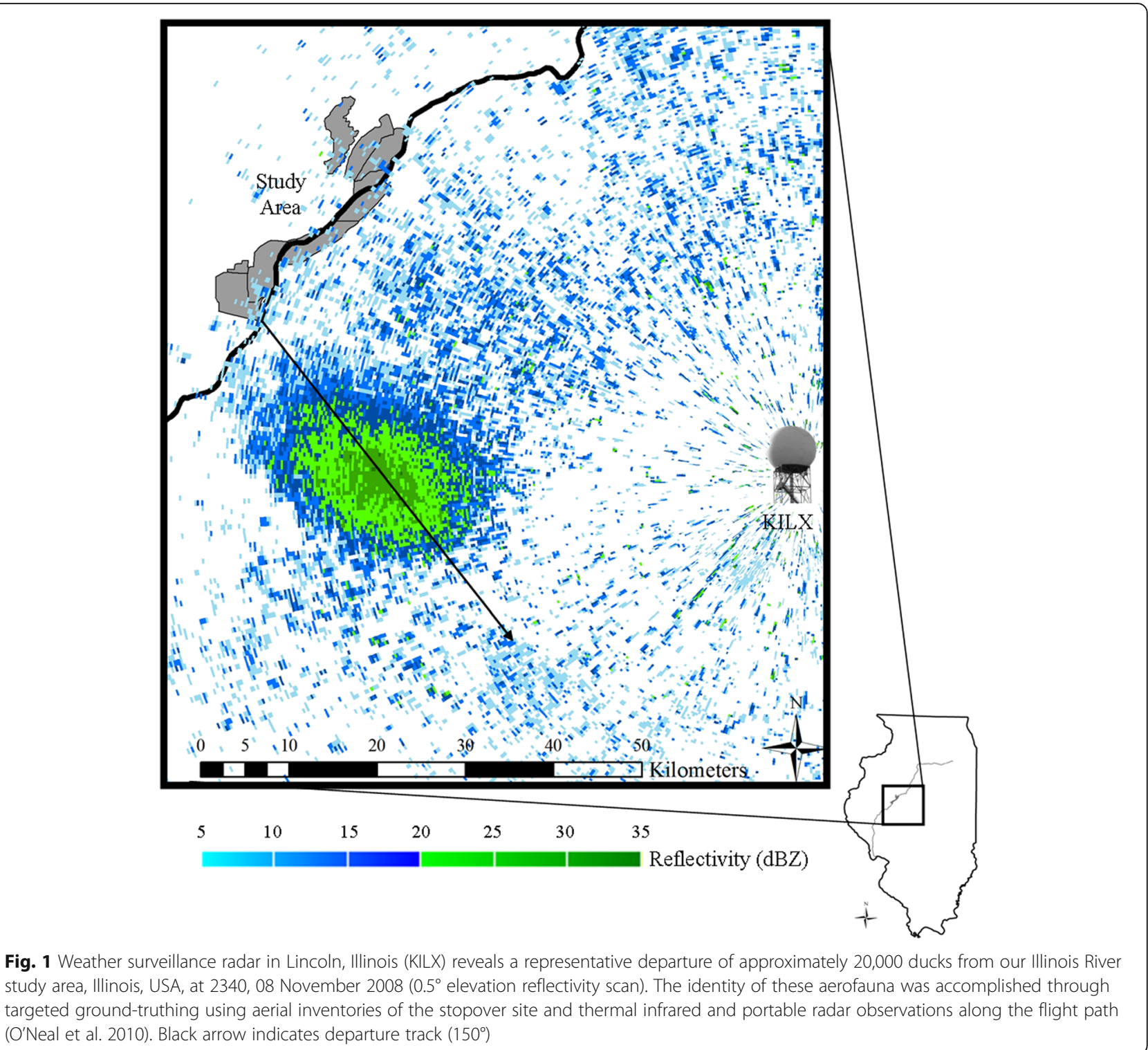

date of the final departure event observed on radar from 1995 to 2009 was December 5.

\section{Weather data}

The National Oceanic and Atmospheric Administration (NOAA) collects and archives a set of standard weather variables intended for various uses. Many of the variables that are collected have relevance for the study of migration based on existing literature. Among these variables, we identified a sub-set of variables that contained adequate temporal coverage to support statistical analysis. Hourly weather variables (precipitation, cloud cover, temperature, pressure, cloud height, and surface wind) were collected in Peoria, Illinois, about $40 \mathrm{~km} \mathrm{~N}$ of our study site (Table 1 and Additional file 1). Because departures occurred at similar times within and among years (2300-0000 GMT; [41; Additional file 1]), we analyzed hourly weather data for the same times on both departure and non-departure days $(\sim 1700$ CST/1800 CDT/2300 GMT). Winds aloft variables were gathered from the nearest radiosonde station, which was located in Lincoln, Illinois, about $60 \mathrm{~km}$ east of our study area (Table 1 and Additional file 1). These data were collected at 0000 GMT (1800 CST/1900 CDT) the night of each departure. We obtained data on mean daily temperature from Havana, Illinois (about $10 \mathrm{~km} \mathrm{SE} \mathrm{of}$ study area; Table 1 and Additional file 1).

\section{Data excluded from analysis}

Our study radar (KILX) did not collect data on 11 possible nights and was obstructed by weather [42] on an additional 11 nights. Weather data were missing for 107 
Table 1 Definition of variables used to explain the probability from stopover sites by autumn-migrating dabbling ducks from 1995 to 2009

\begin{tabular}{|c|c|}
\hline Variable Name & Variable Definition \\
\hline Winds aloft index & $\begin{array}{l}\text { Binary description of the direction of winds aloft at an elevation within the known cruising altitude of ducks in } \\
\text { this region ( } 433 \mathrm{~m} \text { above ground level [26]). Favorable winds (1) are those that are following relative to the } \\
\text { preferred direction of departure from study site } 151.8^{\circ} \pm 0.71^{\circ} \text { (mean } \pm \text { se), and unfavorable winds (0) are those } \\
\text { that are opposing. }\end{array}$ \\
\hline Precipitation index & $\begin{array}{l}\text { Binary description of precipitation status with } 1=\text { No precipitation observed at time of departure ( } 2300 \text { GMT), } \\
0=\text { Precipitation observed at time of departure }\end{array}$ \\
\hline Cloud cover & Proportion of the sky covered by clouds at time of departure $(0 / 8-8 / 8)$ \\
\hline Cloud cover index & $\begin{array}{l}\text { Binary index describing the amount of cloud cover. When stars were completely obscured ( } 8 / 8 \text { cloud cover), an } \\
\text { index of } 0 \text { was assigned; If at least some portion of the stars were visible }(0 / 8-7 / 8 \text { cloud cover), an index of } 1 \\
\text { was assigned }\end{array}$ \\
\hline Cloud height index & Binary index of cloud ceiling height with $1=$ Cloud ceiling $>600 \mathrm{~m} \mathrm{AGL}$ and $0=$ Cloud ceiling $<600 \mathrm{~m}$ \\
\hline Temperature & Surface air temperature at time of departure $\left({ }^{\circ} \mathrm{C}\right)$ \\
\hline $\begin{array}{l}\text { Difference in daily mean } \\
\text { temperature }\end{array}$ & $\begin{array}{l}\text { Difference in mean daily temperatures }\left({ }^{\circ} \mathrm{C}\right) \text { between the } 24-\mathrm{h} \text { period immediately preceding a departure/non- } \\
\text { departure event and the } 24-\mathrm{h} \text { period prior to that day }\end{array}$ \\
\hline Minimum daily temperature & Minimum daily temperature $\left({ }^{\circ} \mathrm{C}\right)$ \\
\hline Barometric pressure at dusk & Barometric pressure at dusk (mb) \\
\hline Change in barometric pressure & Change in barometric pressure from $6 \mathrm{~h}$ prior to departure (1700 GMT) to time of departure (2300 GMT) \\
\hline Foraging habitat index & $\begin{array}{l}\text { Qualitative index of waterfowl food production measured within study area in August/September with } \\
0-2=\text { no or poor food production, } 3-4=\text { fair, } 5-6=\text { good, } 7-8=\text { very good, and } 9-10=\text { excellent } \\
\text { [NA }=\text { Not available] }\end{array}$ \\
\hline Surface wind speed & The rate of horizontal travel of air past a fixed point $(\mathrm{m} / \mathrm{s})$ \\
\hline Julian date & Julian date \\
\hline
\end{tabular}

days. Our modeling analysis prevented use of days lacking data for any covariate, so these days were excluded entirely from analysis, resulting in a final sample of 723 out of 852 possible days (Additional file 1). Omitted dates were distributed within and among years in a non-systematic manner, and we do not believe their omission biased the analysis of departure probability [43].

\section{Model development}

Using the weather variables described above (Table 1) $[11,12]$, we developed a set of a priori candidate models to explain the timing of dabbling duck departures (Table 2). Our candidate model set included one univariate model for each fixed predictor as well as 3 multivariate models. Our response variable had a binomial distribution in which nights with departures were assigned a value of 1 , and those without were assigned a value of 0 [44]. Although the timing of migration is generally controlled less by photoperiod in the autumn than in the spring [45], some studies have shown an effect of seasonality on daily departure probability [20]; therefore, we included year as a random variable within the logistic framework to account for annual variation.

\section{Statistical analyses}

We modeled dabbling duck departure using a logistic regression within a mixed model framework via the glmer function in the lme4 package in Program R [46, 47]. We
Table 2 Names of hypotheses and variables included for each hypothesis used to explain the probability from stopover sites by autumn-migrating dabbling ducks from 1995 to 2009. Predicted direction of effect included in parentheses

\begin{tabular}{ll}
\hline Hypothesis Name & Variables Included \\
\hline WINDSALOFTINDEX & Winds aloft index (+) \\
PRECIPINDEX & Precipitation index (-) \\
CLOUDCOVER & Cloud cover $(-)$ \\
CLOUDCOVERINDEX & Cloud cover index (+) \\
CLOUDHEIGHTINDEX & Cloud height index (+) \\
TEMPERATURE & Temperature $(-)$ \\
MEANDAILYTEMPCHG24HR & Difference in daily mean temperature $(-)$ \\
DAILYMINT & Minimum daily temperature $(-)$ \\
PRESSURE & Barometric pressure at dusk (+) \\
PRESSURECHANGE & Change in barometric pressure $(+)$ \\
HABITAT & Foraging habitat index (-) \\
ORIENTATION & Cloud height index (+), Cloud cover $(-)$ \\
THERMAL & Temperature $(-)$, Difference in daily mean \\
INTEGRATED & temperature $(-)$, Surface wind speed (+) \\
DATE & Winds aloft index (+), Precipitation index \\
Null & $(-)$, Cloud cover index (+) \\
\hline
\end{tabular}


also fit models with a binomial distribution and logit link function. We examined covariates for multi-collinearity based on variance inflation factors (VIF) using the vif function in the car package in Program R [48], but none were $>1.20$, so we retained them all [49]. We evaluated candidate models using Akaike's Information Criterion (AIC) to determine best approximating and competing models [50]. We considered models within $\Delta 2$ AIC units as competing [50]. We derived AIC values, AIC weights $\left(w_{i}\right)$, number of parameters, and model weights in the MuMIn package in Program R. We evaluated model fit by computing marginal (fixed effects only) and conditional (fixed and random effects) $R^{2}$ values according to Nakagawa and Schielzeth [51] using the r.squarredGLMM in the MuMIn package. We calculated odds ratios (OR) and their 95\% confidence intervals (estimated using the Wald method) for covariates in the best model to evaluate their influence on migratory departure (i.e., the odds of departure occurring relative to the odds of non-departure).

\section{Results}

Over our 15-year study period, ducks departed on an average of $30 \%$ of nights each year, with a total of 216 departures out of all 723 nights. The "integrated" model best described the timing of departure relative to weather, capturing all of the model weight $\left(w_{i}=1.00\right)$ and explaining more than half of the daily variation (Conditional $R^{2}=0.55$ ). All other models were $\geq 39.1 \Delta$ AIC (Table 3). Wind aloft $(\beta=3.560,95 \% \quad C I=3.012-$ 4.173), cloud cover $(\beta=1.016,95 \% \mathrm{CI}=0.591-1.451)$, and precipitation $(\beta=2.581,95 \% \mathrm{CI}=0.954-5.487)$ positively affected departure.

Based on coefficient and odds ratio estimates for the best model, ducks were more likely to depart with following winds, no precipitation, and less cloud cover (Table 4). The winds aloft index covariate had the highest OR, indicating the odds of ducks departing with a flight index of 1 as opposed to not migrating were 35.2 to 1 (95\% CI 20.0-62.6). Holding all covariates constant, the probability of ducks departing assuming a flight index of 1 (all conditions favorable) was 0.76 .

\section{Discussion}

Our integrated model, which included following winds aloft, no precipitation, and a less than complete cloud cover, was clearly superior among candidate models describing migratory departure in autumn-migrating dabbling ducks. This model outperformed simpler models in spite of being more parameterized. It also explained over half of the variation in daily departure timing versus non-departure, which was considerably more than previous studies that sought to quantify the
Table 3 Candidate weather models formulated to explain variation in the timing of departure among autumn-migrating dabbling ducks in Illinois River valley, as detected by weather surveillance radar, 1995-2009, ranked by ascending Akaike's Information Criterion (AIC). We included YEAR as a random effect in each model. $w_{i}$ indicates model weight and $K$ indicates number of parameters used in each model

\begin{tabular}{llll}
\hline Model & $\Delta$ AIC & $w_{i}$ & $K$ \\
\hline WINDALOFTINDEX + CLOUDCOVERINDEX & 0.00 & 1.00 & 3 \\
+ PRECIPINDEX & & & \\
WINDALOFTINDEX & 39.10 & 0.00 & 1 \\
PRESSURECHANGE & 182.73 & 0.00 & 1 \\
HABITAT & 233.23 & 0.00 & 1 \\
TEMPERATURE + MEANDAILYTEMPCHG24HR & 235.84 & 0.00 & 3 \\
+ SURFWINDSPD & & & \\
MEANDAILYTEMPCHG24HR & 241.78 & 0.00 & 1 \\
TEMPERATURE & 267.19 & 0.00 & 1 \\
PRECIPINDEX & 270.24 & 0.00 & 1 \\
PRESSURE & 272.39 & 0.00 & 1 \\
CLOUDHEIGHTINDEX + CLOUDCOVER & 275.27 & 0.00 & 2 \\
CLOUDHEIGHTINDEX & 276.57 & 0.00 & 1 \\
CLOUDCOVER & 285.39 & 0.00 & 1 \\
CLOUDCOVERINDEX & 285.66 & 0.00 & 1 \\
DATE & 287.32 & 0.00 & 1 \\
DAILYMINT & 292.71 & 0.00 & 1 \\
Null & 294.81 & 0.00 & 0 \\
\hline
\end{tabular}

relative influence of extrinsic weather conditions on departure decisions of ducks ([14]: $R^{2}=0.19$; [17 (20)]: $\left.R^{2}=0.10\right)$. Contrary to the results of most previous studies on waterfowl, our results suggested weather was indeed an important factor in the timing of autumn migration of dabbling ducks at our study site.

The best model was dominated by the winds aloft index covariate, which had the highest OR of all the covariates. The following or opposing nature of the wind aloft alone explained nearly half of the variation in departure timing $\left(R^{2}=0.47\right.$; Fig. 2$)$. The use of wind data from the altitudes at which ducks migrate rather than the surface likely improved the fit of this model compared to earlier studies [14, 52]. Precipitation also had an important effect, as indicated by the magnitude of the OR. The large CI about the OR of precipitation elucidates the biological nature of its effect. Namely, the presence of precipitation consistently halted migration, but its absence was not a good predictor for the occurrence of migratory departure. Although migratory behaviors differ among Anseriformes and Passeriformes, the weather variables that determine the timing of autumn migration appear to be similar in both taxa [53].

Our results suggest that conditions associated with flight may, in some contexts, be equal to or more important 
Table 4 Estimated coefficients and 95\% Cls as well as odds ratios and 95\% Cls for covariates of the best model (INTEGRATED) explaining variation in daily departure probability of autumn-migrating dabbling ducks in Illinois River valley, as detected by weather surveillance radar, 1995-2009

\begin{tabular}{|c|c|c|c|c|}
\hline Variable & Coefficient & $95 \% \mathrm{Cl}$ & Odds ratio (OR) & $95 \% \mathrm{Cl}$ for OR \\
\hline WINDALOFTINDEX ${ }^{a}$ & 3.56 & $2.98-4.14$ & 35.2 & $19.7-62.6$ \\
\hline CLOUDCOVERINDEX' & 1.02 & $0.59-1.45$ & 2.8 & $1.8-4.2$ \\
\hline PRECIPINDEX & 2.58 & $0.54-4.63$ & 13.2 & $1.7-102.2$ \\
\hline
\end{tabular}

${ }^{a}$ wind aloft index (following winds yielded a value of 1 , opposing winds yielded a value of 0 )

${ }^{b}$ cloud cover index (complete overcast was coded as 0 , and partially clear skies as 1 )

precip index (absence of rain at time of departure was coded as 1 , and presence of rain as 0 )

than local habitat conditions at a stopover. This is in contrast to typical thinking regarding duck migration in the mid-continent $[14,37,38]$, which has typically emphasized the importance of site-specific conditions that influence birds' access to forage (e.g., snow cover and ice) [20, 23]. The general unimportance of weather severity at the local stopover versus the suitability of flight conditions aloft in our study, was probably due in part to the inclusion of early-migrating species (i.e., northern pintail [Anas acuta], green-winged teal $[A$. crecca $]$, American wigeon $[A$. americana], gadwall [A. strepera], and northern shoveler [A. clypeata]), as opposed to only mallards (A. platyrhynchos). The presence of substantial emergent marsh habitat within the Emiquon Preserve is largely responsible for the abundance of non-mallard dabbling ducks within our study complex [54]. Mallards often depart only when forced to do so by severe weather that degrades site-level conditions. However, the suite of dabbling duck species we examined included many obligate migrant species, which would have been more likely to move through the region prior to onset of inhospitable site conditions (i.e., freezing temperatures, frozen surface water, and snow cover). Therefore, the taxonomic composition of our study subjects may partly explain why flight condition models explained departure better than site condition models. The fact that we had to collectively evaluate both early- and late-migrating species of dabbling duck likely explains why DATE did not perform well as an explanatory model for the timing of departure in the entire guild.

Although $55 \%$ of the variation in the timing of departure was explained by our best weather-based model, 45 $\%$ was unaccounted for. Weather conditions such as wind direction and precipitation can vary over relatively small spatial scales. As such, there was likely error associated with the spatial disconnect between the stopover site of interest and the site at which weather data were collected. There may have been additional unexplained variation associated with a "contrast effect," [8, 55, 56] which results in higher departure probabilities when favorable conditions follow unfavorable conditions (i.e., high contrast) rather than similar favorable ones (i.e., low contrast). We did not attempt to model this effect due to its high correlation with weather variables [11]. Disturbance caused by interactions with hunters may also have contributed to unexplained variation in departure timing [15, 18, 44, 57]. Finally, food availability as determined by forage production and density-dependent competition likely affects the overall amount of time

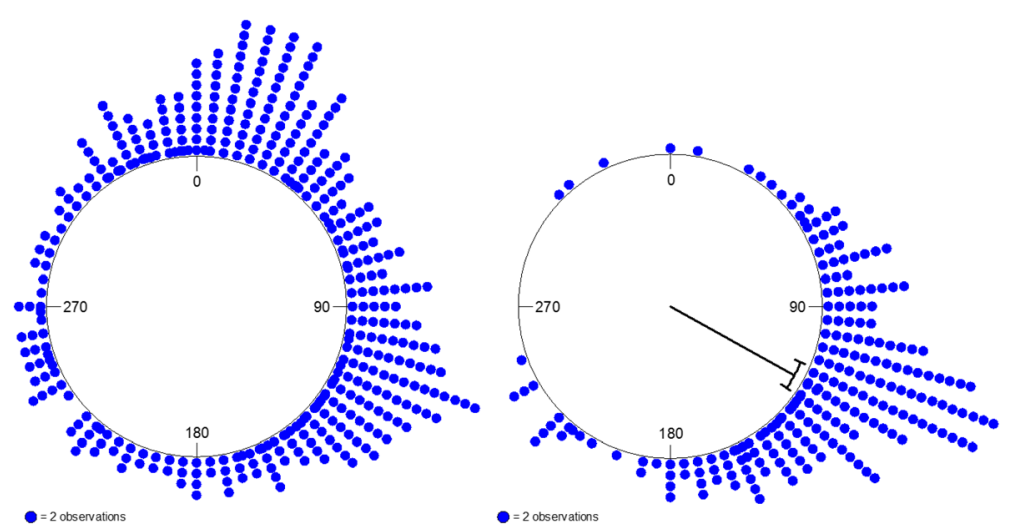

Fig. 2 Frequency distribution of the direction that the winds aloft (433 m Above Ground Level) are blowing toward at $0000 \mathrm{GMT}$ on each night included in our analysis (left) compared to the frequency distribution of the direction that winds aloft are blowing toward at $2400 \mathrm{GMT}$ on a subset of nights on which we observed a departure event 
ducks spend at a stopover, and therefore may have contributed to variation in departure timing in our study [36].

\section{Conclusions}

Our results address some questions regarding the importance of weather conditions in the departure decisions of ducks, but they also raise several others. For example, our results indicated direction of winds aloft was a key factor in departure decisions, but it is unknown how ducks might perceive or sample wind conditions aloft prior to departure. Additionally, the role of non-weather factors (e.g., body condition and hunting) in departure decisions remains unclear and warrants further attention. Finally, our research was conducted during autumn, but considerable questions remain regarding spring migration in ducks [58].

\section{Additional file}

Additional file 1: Migratory departure status $(0=$ no departure, $1=$ departure) for each day included in our analysis and the associated weather conditions for those days (WINDALOFIDIRFROM: Direction from which wind is flowing at 433 $\mathrm{m}$ above ground level; WINDALOFTINDEX: $1=$ Wind aloft is following relative to preferred direction of travel, given obsenved departure tracks over entire study period, $0=$ Wind aloft is opposing relative to preferred direction of travel, given observed departure tracks over entire study period; PRECIPINDEX: $1=$ No precipitation observed at time of departure [2300 GMT], $0=$ Precipitation observed at time of departure; CLOUDCOVER: number of eighths of the sky covered by clouds at time of departure; CLOUDCOVERINDEX: $1=$ Between $0 / 8$ and $7 / 8$ of the sky is covered (i.e., stars are partially visible), $0=8 / 8$ of the sky is covered (i.e., complete overcast); TEMPERATURE: Surface air temperature at time of departure $\left({ }^{\circ} \mathrm{C}\right)$; TEMPCHANGE: Difference in mean daily temperature $\left({ }^{\circ} \mathrm{C}\right)$ between the $24-\mathrm{h}$ period immediately preceding a departure/non-departure event and the 24-h period prior to that day; DAILYMINT: Minimum daily surface air temperature observed for the calendar day $\left({ }^{\circ} \mathrm{C}\right)$; PRESSURE: Barometric pressure $(\mathrm{mb})$ observed at the time of departure; PRESSURECHANGE: Change in barometric pressure over the six hours preceding typical departure (1700-2300 GMT); CLOUDHEIGHTINDEX: 1 = Cloud ceiling $>600 \mathrm{~m}, 0=$ Cloud ceiling $<600$ m; SURFWINDSPD: The rate of horizontal travel of air past a fixed point $(\mathrm{m} / \mathrm{s})$; HABITAT: Qualitative index of waterfowl food production measured within study area in August/September with $0-2=$ no or poor food production, $3-4=$ fair, $5-6=$ good, $7-8=$ very good, and $9-10=$ excellent [NA = Not available]. (CSV $39 \mathrm{~kb}$ )

\section{Acknowledgements}

The authors are especially grateful to A. Yetter and M. Horath of the F. C. Bellrose Waterfowl Research Center for their work conducting aerial inventories. We also thank J. Buhnerkempe, D. Holm and R. Marshalla of the Illinois Department of Natural Resources for their insight and support for the project, R. Warner, E. Heske, and P. Weatherhead of the University of Illinois for their guidance in this research, S. VanEtten and R. Phelps for access to our ground-truthing field sites, G. Sass and A. Yetter of the INHS for use of their field facilities, and J. Planey, B. Kamen, and M. Alessi for their field assistance.

\section{Funding}

This project was funded by the Federal Aid in Wildlife Restoration Fund administered through the Illinois Department of Natural Resources (project W148-R), the Illinois Federation for Outdoor Resources, the Illinois Academy of Science, and the Illinois Prairie Chapter of Delta Waterfowl.

Availability of data and materials

Data used in this study are available reasonable request to the lead author.

\section{Authors' contributions}

$\mathrm{RPL}$, JDS, and BJO conceived this study. Statistical analyses were performed by ESM and BJO with input from JDS, whereas BJO performed spatial analyses. BJO and RPL performed field work. BJO and JDS drafted the manuscript, and all other authors contributed significantly with edits, comments, and revisions. All authors read and approved the final manuscript.

\section{Ethics approval and consent to participate}

Not applicable.

\section{Consent for publication}

Not applicable.

\section{Competing interests}

The authors declare they have no competing interests.

\section{Publisher's Note}

Springer Nature remains neutral with regard to jurisdictional claims in published maps and institutional affiliations.

\section{Author details}

${ }^{1}$ Illinois Natural History Survey, Prairie Research Institute, University of Illinois, Champaign, IL, USA. ${ }^{2}$ Frank C. Bellrose Waterfowl Research Center, Illinois Natural History Survey, Institute of Natural Resource Sustainability, University of Illinois, Havana, IL, USA. ${ }^{3}$ Department of Natural Resource Management, South Dakota State University, Brookings, SD, USA. ${ }^{4}$ Present address: Franklin College, Franklin, IN, USA. ${ }^{5}$ Present address: U.S. Geological Survey, South Dakota Cooperative Fish \& Wildlife Research Unit, Department of Natural Resource Management, South Dakota State University, Brookings, SD, USA.

Received: 16 July 2018 Accepted: 11 November 2018

Published online: 27 November 2018

\section{References}

1. Owen M, Black JM. The importance of migration mortality in non-passerine birds. In: Perrins CM, Lebreton JD, Hirons GJM, editors. Bird population studies: relevance to conservation and management. Oxford: Oxford University Press; 1991. p. 360-72.

2. Sherry TW, Holmes RT. Summer versus winter limitation of populations: what are the issues and what is the evidence? In: Martin TE, Finch DM, editors. Ecology and management of neotropical migratory birds: a synthesis and review of critical issues. New York: Oxford University Press; 1995. p. $85-120$

3. McNamara JM, Welham RK, Houston Al. The timing of migration within the context of an annual routine. J Avian Biol. 1998;29:416-23.

4. Hutto RL. On the importance of en route periods to the conservation of migratory landbirds. Stud Avian Biol. 2000;20:109-14.

5. Dechmann DK, Wikelski M, Ellis-Soto D, Safi K, O'Mara MT. Determinants of spring migration departure decision in a bat. Biol Lett. 2017;13:20180395.

6. Berthold P. Bird migration: a general survey. 2nd ed. New York: Oxford University Press; 2001.

7. Alerstam T, Lindstrom A. Optimal bird migration: the relative importance of time, energy, and safety. In: Gwinner E, editor. Bird migration: physiology and ecophysiology. Berlin: Springer; 1990. p. 331-51.

8. Haest B, Hüppop O, Bairlein F. The influence of weather on avian spring migration phenology: What, where and when? Glob Chang Biol. https://doi. org/10.1111/gcb.14450.

9. Van Doren BM, Horton KG. A continental system for forecasting bird migration. Science. https://doi.org/10.1126/science.aat7526.

10. Notaro M, Schummer M, Zhong Y, Vavrus S, Van Den Elsen L, Coluccy J, et al. Projected influences of changes in weather severity on autumn-winter distributions of dabbling ducks in the Mississippi and Atlantic flyways during the twenty-first century. PLoS One. 2016;2016. https://doi.org/10. 1371/journal.pone.0167506.

11. Richardson WJ. Timing of bird migration in relation to weather: updated review. In: Gwinner E, editor. Bird Migration. Berlin: Springer-Verlag; 1990. p. 78-101.

12. Richardson WJ. Timing and amount of bird migration in relation to weather: a review. Oikos. 1978;30:224-72.

13. Miskimen M. Meteorological and social factors in autumnal migration of ducks. Condor. 1955;57:179-84. 
14. Bellrose FC. The effect of short-term weather conditions on the migration of waterfowl. Final report to the United States Bureau of Sport Fisheries and Wildlife. Washington, DC: Department of the Interior; 1973.

15. Danhardt J, Lindstrom A. Optimal departure decisions of songbirds from an experimental stopover site and the significance of weather. Anim Behav. 2001;62:235-43.

16. Bellrose FC, Crompton RD. Migrational behavior of mallards and black ducks as determined from banding. III Nat Hist Surv Bull. 1970;30:167-234.

17. HM YAP, Stodola KM, Horath MM, Hine CS, Ward MP, Benson TJ, Smith RV, Stafford JD. Stopover duration of mallards during autumn in the Illinois River valley. J Wildl Manag. 2014;78:747-52.

18. Legagneux $P$, Inchausti $P$, Bourguemestre F, Latraube F, Bretagnolle V. Effect of predation risk, body size, and habitat characteristics on emigration decisions in mallards. Behav Ecol. 2009;20:186-94.

19. Roshier D, Klomp Nl, Asmus M. Movements of a nomadic waterfowl, Grey teal (Anas gracilis), across inland Australia: results from satellite telemetry spanning fifteen months. Ardea. 2006;94:461-75.

20. Beason RC. The influences of weather and topography on water bird migration in the southwestern USA. Oecologia. 1978;32:153-70.

21. Nichols JD, Reinecke KJ, Hines JE. Factors affecting the distribution of mallards wintering in the Mississippi Alluvial Valley. Auk. 1983;100:932-46.

22. Pearse AT. Design, evaluation and applications of an aerial survey to estimate abundance of wintering waterfowl in Mississippi. Dissertation. Mississippi State: Mississippi State University; 2007.

23. Schummer ML, Kaminski RM, Raedeke AH, Graber DA. Weather-related indices of autumn winter dabbling duck abundance in middle North America. J Wildl Manag. 2010;74:94-101.

24. Gordo $\mathrm{O}$. Why are bird migration dates shifting? A review of weather and climate effects on avian migratory phenology. Clim Res. 2007;35:37-58.

25. Miller MR, Takekawa JY, Fleskes JP, Orthmeyer DL, Casazza ML, Perry WM. Spring migration of northern pintails from California's Central Valley wintering area tracked with satellite telemetry: routes, timing, and destinations. Can J Zool. 2005;83:1314-32

26. Liechti F. Birds: blowin' by the wind? J Ornithol. 2006;147:202-11.

27. Eikenaar C, Müller F, Leutgeb C, Hessler S, Lebus K, Taylor PD, Schmaljohann $\mathrm{H}$. Corticosterone and timing of migratory departure in a songbird. P Roc R Soc B. 2017;284:20162300.

28. Erni B, Liechti $F$, Underhill KG, Bruderer $B$. Wind and rain govern intensity of nocturnal bird migration in Central Europe: a log-linear regression analysis. Ardea. 2002;90:155-66.

29. Roth RR. Effects of a severe thunderstorm on airborne ducks. Wilson Bull. 1976;88:654-6.

30. Bulyuk VN, Tsvey A. Timing of nocturnal autumn migratory departures in juvenile European robins (Erithacus rubecula) and endogenous and external factors. J Ornithol. 2006;147:298-309.

31. Bellrose FC. Orientation behavior of four species of waterfowl. Auk. 1963;80: 257-89.

32. Matthews GVT. The astronomical bases of 'nonsense' orientation. In: Sibley GC, editor. Proceedings XIII international ornithological congress. Oxford: Blackwell; 1963. p. 415-29.

33. O'Neal BJ, Stafford JD, Larkin RP. Waterfowl on weather radar: applying ground-truth to classify and quantify bird movements. J Field Ornithol. 2010;81:71-82.

34. Blem CR. Energy balance. In: Whittow GC, editor. Avian physiology. 5th ed San Diego: Academic; 2000. p. 327-41.

35. Dawson WR, Whittow GC. Regulation of body temperature. In: Whittow GC, editor. Sturkie's avian physiology. 5th ed. San Diego: Academic; 2000. p. 343-90.

36. O'Neal BJ, Stafford JD, Larkin RP. Stopover duration of fall-migrating dabbling ducks. J of Wildl Manag. 2012;76:285-93.

37. Havera SP. Waterfowl of Illinois: status and management. III Nat Hist Surv Spec Publ. 1999;21

38. Bellrose FC. Ducks, geese, and swans of North America. 3rd ed. Harrisburg: Stackpole Books; 1980

39. Fredrickson LH, Taylor TS. Management of seasonally flooded impoundments for wildlife. Washington, D. C.: Fish and Wildlife Service Resource Publication; 1982. p. 148.

40. Horath MM, Yetter AP, Stafford JD, Hine CS, Smith RV. Illinois waterfowl surveys and investigations. III Nat Hist Surv Tech Rep. 2009;25:1-55.

41. O'Neal BJ, Stafford JD, Larkin RP. Waterfowl on weather radar: applying ground-truth to classify and quantify bird movements. J of Field Ornith. 2010;81:79-90
42. Pyle P, Nur N, Henderson RP, Desante DF. The effects of weather and lunar cycle on nocturnal migration of landbirds at southeast Farallon Island, California. Condor. 1993;95:343-61.

43. Gauthreaux SA Jr, Belser CG. Radar ornithology and the conservation of migratory birds. In: Ralph JC, Rich TD, editors. Bird conservation implementation and integration in the Americas: proceedings of the third international Partners in Flight conference. General technical report, PSWGTR-191. Alisomar: Pacific southwest Research Station, Forest Service, United States Department of Agriculture; 2005. p. 871-5.

44. Cox RR, Afton AD. Predictable interregional movements by female northern pintails during winter. Waterbirds. 2000;23:258-69.

45. Alerstam T. Bird migration. New York: Cambridge University Press; 1990.

46. R Core Team. R: a language and environment for statistical computing. Vienna: R Foundation for statistical computing; 2017. https://www.R-project. org/. Accessed 18 Dec 2017

47. Bates D, Maechler M, Bolker B, Walker S. Fitting linear mixed-effects models using Ime4. J Stat Softw. 2015;67:1-48.

48. Fox J, Weisberg S. An $\{R\}$ companion to applied regression. 2nd ed. Thousand Oaks: Sage Publication; 2011.

49. Kutner MH, Neter J, Nachtsheim CJ, Wasserman W. Applied linear regression models. 4th ed. Columbus: McGraw-Hill/Irwin; 2004.

50. Burnham KP, Anderson DR. Model selection and multimodel inference; a practical information theoretic approach. 2nd ed. New York: Springer-Verlag; 2002.

51. Nakagawa S, Schielzeth $\mathrm{H}$. A general and simple method for obtataining $\mathrm{R}^{2}$ from generalized $R^{2}$ linear mixed-effects models. Methods Ecol Evol. 2013;4: $133-42$.

52. Bellrose FC, Graber RR. A radar study of the flight directions of nocturnal migrants. Proc XII Int Ornithol Congr. 1963;1:362-89.

53. Able KP. The role of weather variables and flight direction in determining the magnitude of nocturnal bird migration. Ecology. 1973;54:1031-41.

54. Hagy HM, Hine CS, Horath MM, Yetter AP, Smith RV, Stafford JD. Waterbird response indicates floodplain wetland restoration. Hydrobiologia. 2016;804: 119-37.

55. Alerstam T. Analysis and a theory of visible bird migration. Oikos. 1978;30: 273-349.

56. Koistinen J. Bird migration patterns on weather radars. Phys Chem Earth B. 2000:25:1185-93.

57. Frid A, Dill LM. Human-caused disturbance stimuli as a form of predation risk. Conserv Ecol. 2002;6:11.

58. Arzel C, Elmberg J, Guillemain M. Ecology of spring-migrating Anatidae: a review. J Ornithol. 2006:147:167-84.

Ready to submit your research? Choose BMC and benefit from:

- fast, convenient online submission

- thorough peer review by experienced researchers in your field

- rapid publication on acceptance

- support for research data, including large and complex data types

- gold Open Access which fosters wider collaboration and increased citations

- maximum visibility for your research: over $100 \mathrm{M}$ website views per year

At $\mathrm{BMC}$, research is always in progress.

Learn more biomedcentral.com/submissions 